\title{
Fixation Mechanisms and Desorption Rates of Sorbed Cs in High-Level Waste Contaminated Subsurface Sediments: Implications to Future Behavior and In-Ground Stability
}

(Project Number: 73758)

\section{Principal Investigator}

John M. Zachara

Pacific Northwest National Laboratory

P.O. Box 999, MSIN K8-96

Richland, WA 99352

509-376-3254 (phone)

509-376-3650 (fax)

john.zachara@pnl.gov

\section{Co-Investigators}

James P. McKinley

Pacific Northwest National Laboratory

P.O. Box 999, MSIN K3-61

Richland, WA 99352

509-375-6861 (phone)

509- 375-6954 (fax)

james.mckinley@pnl.gov

Calvin C. Ainsworth

Pacific Northwest National Laboratory

P.O. Box 999, MSIN K3-61

Richland, WA 99352

509-375-2670 (phone)

509-375-6954 (fax)

calvin.ainsworth@pnl.gov

R. Jeff Serne

Pacific Northwest National Laboratory

P.O. Box 999, MSIN K6-81

Richland, WA 99352

509-376-8429 (phone)

509-376-5368 (fax)

jeff.serne@pnl.gov 


\section{Research Objective}

Research is investigating mineralogic and geochemical factors controlling the desorption rate of

${ }^{137} \mathrm{Cs}^{+}$from subsurface sediments on the Hanford Site contaminated with different types of highlevel waste. The project will develop kinetic data and models that describe the release rates of ${ }^{137} \mathrm{Cs}^{+}$from contaminated sediments over a range of potential geochemical conditions that may evolve during waste retrieval from overlying tanks, or in response to meteoric water infiltration. Scientific understanding and computational techniques will be established to predict the future behavior of sorbed, in-ground ${ }^{137} \mathrm{Cs}^{+}$.

\section{Research Progress and Implications}

This project was initiated on October 1, 2000. Since its inception, we have been investigating ${ }^{137} \mathrm{Cs}^{+}$desorption behavior from contaminated sediments $\left(10^{6}\right.$ to $\left.10^{8} \mathrm{pCi} / \mathrm{g}{ }^{137} \mathrm{Cs}\right)$ from Hanford's S-SX tank farms (41-09-39 and SX-108 boreholes). The sediments were contaminated with Cs-containing redox waste fluids in 1970 that were elevated in temperature $\left(\approx 100^{\circ} \mathrm{C}\right)$ and contained high levels of base $\left(\mathrm{OH}^{-}\right)$, salt $\left(\mathrm{NaNO}_{3}\right)$, and aluminate $\left[\mathrm{Al}(\mathrm{OH})_{4}^{-}\right]$. The highly reactive nature and elevated temperature of the waste fluid induced a complex suite of mineral reactions that decreased in magnitude with increasing distance from leaked tank SX-108. The mineralogic properties of the sediments and the ${ }^{137} \mathrm{Cs}$-hosting micaceous sorbents in the contaminated sediments were characterized in detail using techniques such as x-ray absorption spectroscopy and transmission electron microscopy.

Desorption kinetic studies were performed in batch mode in $\mathrm{Na}^{+}, \mathrm{K}^{+}$, and $\mathrm{Rb}^{+}$electrolytes and in the presence of a Cs-selective adsorbent. Three separate adsorbed pools of ${ }^{137} \mathrm{Cs}^{+}$were defined: 1) a rapidly exchangeable pool ( $\approx 20 \%$ to $25 \%), 2)$ a kinetically exchangeable pool $(\approx 15 \%$ to $20 \%)$, and 3 ) a poorly exchangeable or fixed pool $(\approx 60 \%)$. The kinetics of desorption was complex and was influenced by the hydration status of the exchanging cation. Poorly hydrated cations such as $\mathrm{Rb}^{+}$and $\mathrm{K}^{+}$induce collapse of mica edges, which, in turn, physically prevents ${ }^{137} \mathrm{Cs}^{+}$desorption. A multisite exchange/slab diffusion model was developed that well described the Cs desorption process in all four sediments studied, as well as the observed experimental results in different electrolytes (see Figure 1 for examples of results and model simulation). The physical model was based on X-ray microprobe measurements of Cs distribution in micaceous particles, where Cs was found to be localized to specific areas on the mica edge and in connected cleavage channels running parallel to the $\mathrm{C}$ crystallographic axis.

The results are immediately useful to the Department of Energy (DOE)-Hanford Site. Of major significance, our work has shown that approximately $60 \%$ of the in-ground ${ }^{137} \mathrm{Cs}^{+}$pool in the S-SX tank farm is immobile and is unlikely to desorb from the sediments under any reasonable geochemical scenario. Thus, our research has reduced by more than $50 \%$ the effective in-ground 


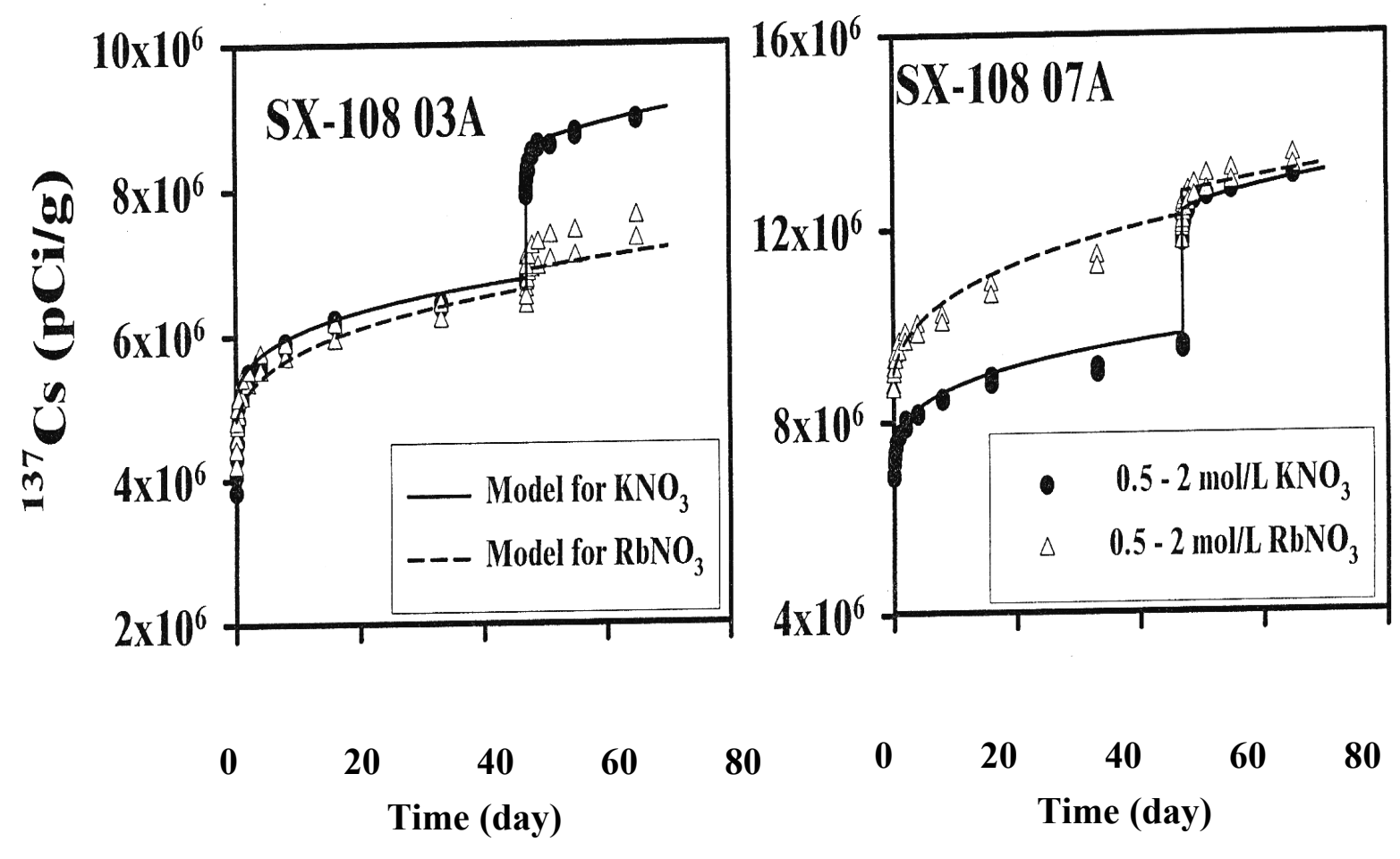

Figure 1. Kinetic desorption data for the release of $137 \mathrm{Cs}+$ from two contaminated sediments collected beneath leaked Hanford tank SX-108. The sediments were first placed in $0.5 \mathrm{~mol} / \mathrm{L} \mathrm{KNO} 3$ or RbNO3, and desorption was followed for approximately $50 \mathrm{~d}$, after which the electrolyte concentration was increased to $2 \mathrm{~mol} / \mathrm{L}$ by addition of solid electrolyte salt. The increased $137 \mathrm{Cs}+$ desorption resulting from the mass action effect of the electrolyte salt was followed. The solid and dashed lines represent the results of simulations with the slab diffusion model. The two sediments differ in the fraction of $137 \mathrm{Cs}+$ that is desorbed by $\mathrm{Rb}+$, a result of mineral transformation caused by reaction with high base in the REDOX waste supernatant.

inventory of ${ }^{137} \mathrm{Cs}^{+}$that needs be considered from the risk perspective. Moreover, our model and associated database allow prediction of the rate and amount of the exchangeable ${ }^{137} \mathrm{Cs}^{+}$fraction that may desorb from contaminated sediments, depending on the composition of the vadose zone porewater (i.e., whether it originates from rainwater infiltration or leakage during single-shell tank waste recovery).

\section{Planned Activities}

Research in the remaining 1.5 project years will focus on ${ }^{137} \mathrm{Cs}^{+}$-contaminated sediments from the B-BX-BY and T-TX-TY tank farms that have received bismuth phosphate wastes as well as wastes from B-Plant and the Plutonium-Uranium Extraction (PUREX) facility. The different major-ion chemistries of these three process wastes may have driven different suites of reactions that impact Cs desorption. Such factors will be evaluated through a well formulated set of 
desorption kinetic experiments. Over this 1.5-year period, time-of-flight and dynamic secondary ion mass spectroscopy, transmission electron microscopy, and other state-of-the-art science techniques will be applied in efforts to map the depth distribution and structural association of sorbed Cs in mineral particles isolated from the contaminated sediments. These latter measurements will refine our physical model of Cs sorption location in mineral particles, improving our kinetic ${ }^{137} \mathrm{Cs}^{+}$model.

\section{Information Access}

Zachara JM, SC Smith, C Liu, JP McKinley, RJ Serne, and P Gassman. 2002. Sorption of Cs ${ }^{+}$ to Micaceous Subsurface Sediments from the Hanford Site, USA. Geochim. Cosmochim. Acta, 66:193-211. 